\title{
Education Quality of Best Public High Schools in South and Central Somalia
}

\author{
Abdi Hashi Nur \\ Indiana State University \\ Terre Haute, IN, USA
}

\author{
Ali Abdi Farah \\ Walden University \\ Minneapolis, Minnesota
}

\author{
Omar Mohamed Warsame \\ The Holy Quran and Islamic Science \\ Khartoum, Sudan
}

Received: May 7, 2021. Revised: July 13, 2021. Accepted: July 15, 2021. Published: July 20, 2021.

\begin{abstract}
The purpose of this study was to explore what nine high school principals did to outperform other schools in the South and Central regions of Somalia. The study highlighted the high school principals' perception of maintaining education quality concerning curriculum, instruction, and assessment. The study focused on the admission process, teaching, and learning performances of the top nine high schools in South and central Somalia. The methodology of this Qualitative study was descriptive phenomenology. The research design and approach were semistructured open-ended interview protocol that comprised eight interview questions. Purposeful sampling was the sampling method. Nine principals participated in the study and provided the research data regarding the education quality of nine high schools in Somalia. All nine principals in this study maintained their high schools' education quality using a rigorous admission process. They utilized a government-developed official curriculum. Five principals reported that they employed specialist instructors, while six stated that their students actively participated in the learning process during class time. However, all the participants reported that smartphones hindered student learning. A slight majority of five principals $(\mathbf{5 6 \%})$ stated that parental interventions were vital to schools' overall learning achievements. Somalia's public schools are far behind in utilizing effective educational technology. The technological literacy of the teachers is vital to effectively employ the accessible educational technology, which encouraged students to incorporate modern technologies in their learning activities successfully. Rigorous admission process, efficient curriculum, instruction, effective instructional materials, employing professional
\end{abstract}

instructors, and active learning are all important components to maintain education quality.

Key words: quality of education, curriculum and instruction, assessment, active learning

\section{INTRODUCTION}

After Somalia gained independence, the government initiated an all-inclusive formal education system, and it had been a priority for Somali governments [1]. The downfall of the Somali state in 1991 had an overwhelming effect on the country's education, where a whole generation had lost their most significant childhood opportunities [2]. Since the collapse of the state, Somalia's government-run education system failed, Somalia's literacy rate, which in the 1970s reached a record high of 55 percent [3], sharply dropped after the regime's fall [4]. Thus, the quality of education descended to the world's bottommost nations [5]. For the above reasons, only 26.5 percent of high school-aged youths are at high school [6]. There was a transformation of the Somali education system from government-provided free education into almost private service [1]. (Hassan, 2016), which is of poor quality and available for those who can afford it. With the downfall of the nationstate, there had been no opportunity to discuss and formulate a coherent strategy for the education sector as a whole or decide how to devise a countrywide system until recently [2]. Nevertheless, there were some pockets of public schools in South and Central regions. The ministry of education introduced the first curriculum in 2019, and South and Central regions adopted it in the 2019/2020 school year. The present study explores the quality of the education of the best high schools in South and Central Somalia regarding curriculum, instruction, and assessment. 


\section{BACKGROUND}

This study explores what assisted the best nine high schools in South and Central Somalia to outpace other high schools in these regions in the 2019/20 schoolyear regarding curriculum, instruction, and assessment. The three most significant and interconnected aspects of education are curriculum, instruction, and assessment [7]. Curricula ensue from a procedure that mirrors societal agreement about what, why, and how of education, which is desirable for the society in the future [8]. Bringing many subjects concurrently in teaching and learning is known by different names [9]. The curriculum is the one that we use in this article. The curriculum encompasses the subjects' knowledge and abilities that instructors teach, and students must learn [7]. Citing [10]-[11], there are two curriculum design types, which are Powerful Knowledge and 21st Century Learning [12].

The Powerful Knowledge curriculum grounds on a very broadly based research program [13]-[14]-[15]. This curriculum type follows the Durkheimian social realist method, which focuses on understanding how knowledge production and reproduction happens [12]. The 21st Century Learning states a social justice purpose, reasoning that the significance of skills and adaptable dispositions method will augment opportunities, especially for those from marginalized communities [12]. The 21st Century model did not regard that education is sufficiently receptive to a complex, globalized world in which skills, critical thinking, adaptability, and creativity will be more significant than knowledge by itself. We are not sure of which type of curriculum design the Somali ministry of education used to prepare the 2019 curriculum. A research study [16], cited in [17], stated that curriculum preparation could be complex; therefore, the involvement of all stakeholders, especially individuals who are directly involved in student instruction, is paramount to its successful production and reconsideration.

The curriculum development to be efficacious, and for schools to be fruitful, it is significant to involve teachers in the development process [17]. The curriculum development is a process in which fulfilling student requirements guides student learning enhancement [17]. However, in post-civil war Somalia, researchers of this study could not identify whether teachers were involved in the curriculum development stages. Somalia ministry of education adopted in 2019 a new public-school curriculum, which is the first of its kind in three decades.
A controlling entity should check the quality of the curriculum [18]. In Somalia, the controlling body can be the education ministry or an independent advisory board that provides the necessary guidance to the ministry of education. The evaluation of a curriculum's quality must be against specific quality standards [19]. Curriculum assessment is a method of collecting and analyzing data from various sources to enhance student learning in sustainable means [20]. Once the curriculum is outlined and approved, the task moves to the instruction.

Instruction is the teaching approach, and the learning actions teachers use to help students grasp the content and the goals detailed in a curriculum [17]. Teachers face five tasks when implementing a curriculum: "coverage, mastery, management, positive effect, and evaluation" [21-192]. Teachers espouse better learning because they have the knowledge and experience of teaching, and society trusts them for presenting the curriculum in the classroom [17]. Teachers must cover the program's components, such as contents, skills, and objectives. They must ensure that students learn the topics at least at some minimal level of understanding. Learning is more significant if the providers structure it around concepts germane to students and the world beyond school [22]. Besides the coverage and mastery tasks, teachers need to focus on managing the classroom and the students. This task can be accomplished by engaging students positively toward the subject matter in the class. Along with quality curriculum and instruction, assessment is the third most significant aspect of education.

The last task for teachers to achieve is to evaluate students' progress and what kinds of topics students must be held accountable for learning [21]. The assessment refers to how teachers use it to ensure that students understood the curriculum's contents [7]. In Somalia, teachers assess secondary school students' level of educational performance for the first three years. However, assessment comes from the education ministry as a centralized exam that all Somali students must pass to achieve a secondary school leaving certificate at the end of the fourth year. Out-of-date theories base the curriculum, instruction, and assessment and not inline the modern educational system [7]. There must be an alignment of the three education aspects discussed earlier, which means that they must be directed towards the same goal and enforce each other instead of aiming at different purposes [7]. 


\section{METHODOLOGY}

The purpose of the current study is to explore what helped Somalia's best nine high schools outpace other high schools in South and Central regions in the country in the 2019/20 schoolyear regarding curriculum, instruction, and assessment. The present study's methodology is phenomenology, which scholars defined as a philosophy, a research paradigm, a method, and associated with qualitative research [23]. Phenomenology is a qualitative method in which researchers aim to create new understandings of peoples' lived experiences [24]. We selected this approach because it concerned the principals of ten schools' lived experiences, which became the top high schools in the 2019/2020 school year in South and Central Somalia. Unlike methods, which is how a researcher undertakes the study, methodology speaks about the research methods' idea: why did the researcher select interviews, surveys, observation, audio recordings, or get the participants to draw pictures [25]?

The information gathering methods, which researchers use more often in qualitative inquiry, are participant observation, interviews, and focus group discussions [26]. The data collection method of this study was semi-structured interviews. The sampling method of this investigation was purposeful sampling. Data saturation occurred after all nine participants' interviews finished. The participants' selection criterion was their knowledge and experience of achieving the top nine secondary schools in South and Central Somalia in 2019/2020. Before conducting interviews, the interviewer built a good rapport with the participants, described the investigation's purpose and the interview time to the interviewees. A telephone interview was the data collection strategy because the researchers and the participants lived in different countries. Each interview lasted between 30 to 60 minutes.

According to the Ministry of Education, Culture \& Higher Education press release [27], Table 1 shows school name, school location, school ranking, and average test scores of each school.
Table 1

Hight Schools with Ranking and Average Points

\begin{tabular}{llcr}
\hline Schools & $\begin{array}{l}\text { School } \\
\text { Location }\end{array}$ & Ranking & $\begin{array}{r}\text { Ave. Test } \\
\text { Scores \% }\end{array}$ \\
\hline Afmadow & Afmadow & 5 & 84.12 \\
Al-Anwar & Garboharey & 1 & 86.78 \\
Al-Qalam & Baydhabo & 7 & 81.33 \\
Amiir Nur & Garboharey & 2 & 85.97 \\
Luq Ganane & Luuq & 3 & 85.19 \\
Macruuf & Baydhabo & 6 & 81.43 \\
Markabley & Baardhere & 4 & 84.44 \\
Omar Bin Abdiaziz & Guriceel & 8 & 80.98 \\
Salahudin & Baydhabo & 9 & 80.84 \\
\hline
\end{tabular}

The interviewer used open-ended questions to gather information from the principals. The interview included opening questions about the respondents' background, such as their profession and education levels. The interview protocol comprised eight questions, and the interviewer refined the questions through pilot testing. The numbering of all data was a chronological order of their occurrence [28]. The participants answered different types of questions regarding their high school assessments. Questions regarding the types of evaluations included placement and performance assessments before they join the new schools. It also contained bimester and quadrimester formative reviews to examine the students' learning progress during the school year. The schools conducted summative assessments at the end of the instruction to assess how they achieved the desired objectives and the learning goals. The interviewer used phenomenological bracketing and reduction to diminish the possible researcher biases or impact of his previous knowledge on the participants' responses to the data collection and analysis stages.

During the data analysis, we used Giorgi's four-stage information analysis model [29]. This model involves: Reading through the transcripts several times to gain a comprehension of the whole. Establishing the natural meaning units as the participants describe them. Cross-examining the meaning units in terms of the precise aim of the study. After recognition of the themes, incorporating the essential nonredundant concepts into a descriptive statement. Giorgi recommended that the researcher must read the transcript recurrently while employing phenomenological reduction [29]. Eight themes 
emerged after coding and categorization of the data. The descriptive statements of the essential nonredundant themes are in the below section.

\section{RESEARCH FINDINGS}

The following primary research question guided the present study: What helped Somalia's top nine high schools outperform other high schools in South and Central Somalia in the 2019/20 school year regarding curriculum, instruction, and assessment? Eight main themes emerged from the qualitative data analysis (See Table 2): a) rigorous admission process, b) operational curriculum, c) effective instructional materials, d) professional instructors, e) active learning, f) modern technology obstacles, g) routine assessments, and h) school management and parental intervention. These themes are the themes that five participants or more agreed-upon qualify to include in the final list.

Table 2

Final Themes with Supporting Participants

\begin{tabular}{lcc}
\hline \multicolumn{1}{c}{ Themes } & $\mathrm{N}$ & $\%$ \\
\hline Rigorous admission process & 9 & 100 \\
Using operational curriculum & 9 & 100 \\
Effective instructional materials & 9 & 100 \\
Modern technology obstacles on learning & 9 & 100 \\
Routine assessments & 9 & 100 \\
Management and parental intervention & 9,5 & 100,56 \\
Active learning & 6 & 67 \\
Professional instructors & 5 & 56
\end{tabular}

\section{A. Theme 1: Rigorous Admission Process}

The qualitative data findings indicated that all school principals (100\%) interviewed in this qualitative study maintained their high schools' education quality by accepting only students who completed registered primary and middle schools and transfer students from similar high schools. The respondents reported that students could only transfer from governmentregistered high schools. The participants reported more categories associated with the rigorous admission process theme, such as taking a placement test, transfer students should bring report forms, and no admission to students who fail the placement test.

Eight school principals, or $89 \%$ of the participants, reported that students who transferred from other registered schools should take an assessment test before acceptance, i.e., the assessment test determined whether transfer students could join the high school or not. They stated that their high schools prepared an assessment exam for high school transfer students. If students failed the assessment exam, they were not allowed to join their schools. But transfer students who passed the assessment test could join their high schools. Also, six participants, or $67 \%$ of the school principals, stated that transfer students must bring school report forms for the admission process.

\section{B. Employing Operational Curriculum}

Nine principals $(100 \%)$ posited that they utilized a government-developed national curriculum. Eight principals $(89 \%)$ noted another significant category associated with education quality based on curriculum was an effective official curriculum. They stated that the Ministry of Education of the Federal Government of Somalia introduced a new curriculum in the 2019/20 schoolyear. They taught history and geography courses in the Somali language; English was the language of science courses. Arabic was the medium for some subjects.

Eight school principals, or $89 \%$ of the participants, reported that the official curriculum was effective and compatible with their schools' instructional requirements. They stated that the current official curriculum was effective and addressed its educational needs for a unified national curriculum. It was a wellbalanced curriculum, which was compatible with instructional needs. Participants reported that students were happy with the newly developed official curriculum.

\section{Effective Instructional Materials}

Nine principals $(100 \%)$ asserted that they based their high schools' education quality on schools' basic instructional supplies, i.e., textbooks, blackboards, and chalks. Other significant categories associated with education quality based on instructional materials included projectors, which six principals $(67 \%)$ reported they used in addition to the essential instructional resources. Five principals (56\%) asserted that computers were included the instruction materials.

P 7 stated that his school used blackboards, chalks, and a projector, which teachers sometimes used for practical lectures. He reported that his school had computers occasionally for only high school students, adding that all schools employed blackboards and chalk as the fundamental materials to educate students. 


\section{Professional Instructors}

Five principals, or $56 \%$ of the interviewees, stated that they employed specialist instructors. The narrative these principals asserted was that they managed their schools voluntarily for many years and not received any form of assistance from governmental or nongovernmental organizations. They said that their schools' policies were to hire only specialist teachers and teachers with significant experiences for the courses they taught. They posited that their teachers were specialists except for one or two highly experienced longtime instructors. However, four participants, or $44 \%$ of the principals, stated that their high schools had a mixture of generalist and specialist instructors.

\section{E. Active Learning}

Nine principals $(100 \%)$ interviewed in this investigation asked students questions during class time about the subject matter. However, six principals $(67 \%)$ stated that active learning was another significant category where students participated in the learning process during class time. All participants reported that their schools' teaching methods included asking students oral questions during classroom time. They posited that their schools' teaching and learning process to transmit knowledge was student-centered. Teachers and students worked together by sharing knowledge. Also, six (67\%) school principals reported that students were active learners who participated in class activities as part of their high schools' teaching methods.

\section{F. Modern Technology Obstacles on Learning}

All principals (100) reported that mobile and smartphones hindered student learning. Seven participants (78\%) stated mobile and smartphone prohibition in schools as a category, and their schools confiscated mobile and smartphones. Five principals $(56 \%)$ of the participants indicated that social media hurt student learning.

Nine principals $(100 \%)$ stated that mobile and smartphones negatively influenced students' learning, i.e., these technologies hindered students' learning. They asserted that their schools focused on good behaviors. Most of the schools prohibited mobiles and smartphones. If students bring mobiles and smartphones to school, teachers confiscated them and gave them to parents. Eight school principals (89\%) stated that they prohibited mobile and smartphones in schools. Five participants $(56 \%)$ reported that their schools confiscated smartphones and mobiles found with students in the schools, and five school principals $(56 \%)$ stated social media negatively affected students' learning.

\section{G. Routine Assessments}

All school principals (100\%) performed teaching and learning assessments of their high schools by administering midterm and final exams. They reported their schools issued midterm examinations within four months from the beginning of the school year and final exams at the end of the school year. They stated their schools administered monthly exams as a routine formative assessment, which helped them assess students' performance levels in the past month. They took midterm exams to evaluate school performance levels and their learning performance for the past four months. They administered final exams as summative assessments at the end of the school year.

Eight principals (89\%) stated they administered monthly exams. Teachers asked students in the classroom routine oral questions about the lectures. They noted that the teachers routinely asked students oral questions as part of assessments. Teachers collected verbal questions from the contents of the courses.

\section{H. School and Parental Intervention}

All participants $(100 \%)$ stated that they maintained their schools' education quality through management intervention. They posited that the high school administration routinely evaluates the performance levels of the schoolteachers. Besides, five principals $(56 \%)$ stated that parental intervention positively contributed to their overall learning activities. They reported that the school administrators encouraged parental involvement in students' learning activities.

\section{DISCUSSION}

The authors attempted to explore what Somalia's topranking high schools in South and Central had in common to outperform other high schools in that region in the 2019/20 school year concerning curriculum, instruction, and assessment. Assessing transfer students before their admissions confirmed what was in the literature of the high school admission process. Introducing assessment tests for students who transfer to higher grade levels boosted students' learning achievements [30], i.e., these evaluation exams positively impact students' learning success. Hence, our results affirmed that assessment tests within the admission process were vital to maintaining the high schools' education quality in the present 
study. Admitting to high schools only those students who formally and completed primary and middle schools were central to maintain the education quality of the high schools, as showed by the results of this study. Besides, employing an effective curriculum by the high schools was key to productive learning outcomes through which principals successfully maintained the quality of education. The statement is consistent with previous research finding where [31] studied teachers' and students' positions on effective curriculum. The researchers found that an efficient curriculum that values and respects students' social and emotional learning is vital to successful educational achievements. A variety of curriculum resources equipped with their research participants to meet students' needs better and enhance mastery of learning objectives [32].

Most of the high school principals in this study employed subject-matter specialists who they described as crucial to their high school success. This finding is consistent with a research conclusion, where most principals in a study used subject-matter specialists whose knowledge was essential for teaching school subjects [33]. Specialized schoolteachers bring greater self-confidence to the classrooms [34]. The specialist instructors used their specific experiences to empower students to learn course contents effectively [35]. Factors causing students' poor performances in schools include teachers' qualifications, their method of instruction, their teaching experience, and their lack of using practical instructional resources [36].

This study also explored the instructional materials of the high schools. The current study participants acknowledged the importance of teaching resources to maintain education quality to improve students' learning capacity. That is in line with a previous study finding where teaching resources could make students enhance their learning performances [37]. Our study results showed that the high schools used basic teaching materials, including blackboards, chalks, and textbooks, to support learning. Modern technologies could advance education [38]. Educational technologies such as videos, online recordings, presentations, and typing could deliver knowledge more efficiently. However, differing results exist in the effectiveness of the basic and the modern teaching instruments, including videos, displays, blackboards, chalks, projectors, and online open technologies [39]. Schools need support with appropriate instructional materials critical to increasing instruction effectiveness [40]. Hence, our study results suggested that more than half of the study participants reported their high schools used projectors and computers, and other essential instructional resources.

The concept of active learning is an option to traditional education [41]. Unlike teacher-centered learning, students collaborate in student-centered learning. The present study participants admitted that students' active learning was a crucial part of the high schools' teaching and learning techniques. However, they acknowledged that modern technologies disrupted students' active learning, i.e., smartphones and social media impact students' capacity to engage in learning actively. Nonetheless, our results indicated that teachers empowered students to participate in class activities actively. Teaching with active learning among students leads to students focusing more on the lesson [42]. This finding is consistent with a previous result where, as part of active learning, all study participants reported schoolteachers routinely engaged with students by, for instance, asking oral questions about the lectures [43]. A previous study classified class activities as part of students' active learning [44]. Instructors explicitly ask students to actively engage in the learning process, i.e., class discussions and answering teachers' oral questions. Best practices in active learning help students to engage in course discussions so they can learn from each other [45].

Modern technologies enable learners a wide variety of learning activities and informal learning experiences [46]. Technologies provide prospects for learning new skills and offer new approaches to learning traditional experience [47]-[48]. In contrast with these statements, our study results showed that smartphones, mobiles, and social media hindered student learning. While we did not explore the use of these modern technologies in education by the schools, our study participants unanimously reported that their high schools spent a significant amount of time on social media and smartphones. We believe students were not encouraged to use technologies to advance learning effectively. We assume that the schools in our study lacked the expertise and the knowledge to successfully employ educational technology skills to minimize the negative influence of smartphones, mobiles, and social media on students' learning.

Assessments are essential for teachers' and students' teaching and learning performances [49]. Formative assessments (FA) conducted at earlier stages of instruction can guide lesson planning and subsequent evaluations. Instructors apply FA to develop effective instruction and assessment tools that satisfy student learning needs [49]. FA improved students' learning outcomes, and its introduction into everyday school practice is significant [50]. FA helped examine the 
students' learning performance in university students' research [51]. The researchers reported that FA significantly improved students' learning outcomes. In line with the above statements, our results show that the high schools maintained the education quality by conducting monthly and midterm exams to improve student learning outcomes. The study participants unanimously reported routine final exams as a summative assessment to retain the quality education of the schools.

\section{IMPLICATIONS FOR PRACTICE}

The current study's focus was to address the quality of education in public high schools in Somalia as a whole. Hence, we investigated the top nine public high schools' education performance in the South and Central regions of the country. The findings of this study could help the education community in Somalia find ways to effectively boost education quality regarding teaching and learning activities in public and private schools.

Accordingly, the current study provides empirical data on the benefits of employing a rigorous admission process, operational curriculum, adequate instructional resources, and professional instructors. The data is essential to develop the quality of education by integrating a well-organized system of teaching. This study identifies the need for technological literacy among public schoolteachers to effectively educate students by utilizing accessible educational technology tools such as smartphones, mobile phones, and social media. The study showed how these technologies hindered students' learning activities rather than helping. Educators may need to encourage students to incorporate modern educational technologies with learning activities in and outside classrooms.

Finally, the findings of this study suggest that robust assessment routines are vital to maintaining education quality. The results could explain how educators should routinely use formative and summative assessments to ensure the teaching and learning goals. The study findings also underlined the significant role of parent contributions to students' learning, i.e., educators can rely on parents' positive involvements in student learning outside classrooms.

\section{LIMITATIONS}

There are few limitations to the present study. A major limitation of this study is that its findings are not generalizable as quantitative studies' findings. The base of the research data was on participants' responses. Therefore, the researchers had no control over how honestly participants responded to the questions from the interview guide. Although the researchers used phenomenological bracketing during data collection and analysis, it is challenging to diminish researcher biases. Data from one of the topranked high schools were missing due to the inaccessibility of the school principal at the time of this study and the recruitment venue. That might have provided valuable information.

\section{RECOMMENDATIONS}

Several opportunities exist for further research to explore the impacts of the findings on the quality of education in the country. The participants indicated that they had rigorous placement tests and vetting processes before new students join in their high schools. Also, they stated that they employed qualified and experienced instructors. Further research may find whether the curriculum and quality of intrusion are the main factors of the schools' achievements, or the rigorous vetting process, or the students' participation and efforts are the success factors. The study participants stated that they switched to the new Ministry of Education's curriculum as soon as the Ministry of Education introduced it. Further research on how a change of curriculum affected the students' learning capacity and whether it had any psychological effects on them or not is necessary.

The country's number one ranked high school presented laptops to students, and it is not clear whether that technological factor boasted the students' learning abilities. Further study on the effects of the technology factor is necessary. This study did not investigate the education quality of the outpaced high schools in South and Central Somalia. Hence, future research may need to compare the education qualities of different high schools in these regions and Somalia. Further research into the differences between the quality of education of the top schools and the others is necessary. Finally, replication of the study in other similar situations may prove whether the findings of this investigation are transferable to different situations or not.

\section{CONCLUSION}

The current study contributes to the quality of education in Somalia by looking into relevant data from the top nine high schools in the country's South and Central regions. The study explored what facilitated those nine high schools to outpace other high schools in the 2019/20 school year. The findings of the study have shown the positive impact on the 
education quality by the rigorous admission process, efficient curriculum and instruction, effective instructional materials, and competent professional instructors. Active learning in and outside classrooms, regular assessments, effective school management, and routine parental interventions were the key findings in this study to maintain education quality for the nine public high schools.

The current study has also revealed how Somalia's public high schools are far behind in utilizing effective educational technology. The teachers' technological literacy is vital to effectively employ accessible educational technology, which can encourage students to successfully integrate modern technologies in their learning activities. Contrariwise, the findings of the present investigation have proven how the basic modern educational technologies, i.e., smartphones and mobile phones with internet connections hindered the quality of education rather than effectively utilizing them for teaching and learning purposes.

Finally, the study results can be a good foundation from which future research can probe what factors can improve the country's quality of education in public schools, and the factors that may hinder productive learning. The findings of this study support the existing literature on the quality of education.

\section{REFERENCES}

[1] Hassan, Z. (2016). Somalia's education system: towards accessibility, inclusiveness, and quality education. Horn Economic and Social Policy Institute (HESPI), 41.

[2] Cassanelli, L., \& Abdikadir, F. S. (2008). Somalia: Education in transition. Bildhaan: An International Journal of Somali Studies, 7(1), 7.

[3] Abdi, A. A. (1998). Education in Somalia: History, destruction, and calls for reconstruction. Comparative Education, 34(3), 327-340. Retrieved from http://ezproxy.indstate.edu:2048/login?url=http://sear ch.proquest.com/docview/195149351 ?accountid=115 92

[4] Anagnoste, S., Agoston, S., Draghici, M. (2009). How to manage an economy outside the system. Annals of DAAAM \& Proceedings, 20(1), 109-110.

[5] Helping Somalia recover and develop: European commission to invest extra euro 175 million in governance, education and food security. (2011, Aug 05). African Press Organization. Database of Press Releases Related to Africa. Retrieved fromhttp:// ezproxy.indstate.edu: 2048/login?url=http://search. proquest.com/docview/881099941 ?accountid=11592
[6] United Nations International Children's Emergency Fund. (2018). UNICEF Somalia education strategy note 2018-2020.http://files.unicef.org/transparency/ documents/Somalia\%204. \% 20Education.pdf

[7] Pellegrino, J. W. (2006). Rethinking and redesigning curriculum, instruction and assessment: What contemporary research, and theory suggests. Commission on the Skills of the American Workforce, Chicago, 1-15.

[8] Tedesco, J.C., Opertti, R. \& Amadio, M. (2014). The curriculum debate: Why it is important Today. Prospects 44, 527-546.https://doi.org/10.1007/s111 25-014-9326-X

[9] McPhail, G. (2018). Curriculum integration in the senior secondary school: A case study in a national assessment context. Journal of Curriculum Studies, 50(1), 56-76. https://doi.org/10.1080/00 220272.2017.1386234

[10] Young, M., \& Muller, J. (2013). On the powers of powerful knowledge, Review of Education, 1(3), 229. 250.

[11] Delors, J. (Ed.). (1998). Education for the twenty first century. Paris: United Nations Educational, Scientific and Cultural Organization.

[12] McPhail, G., \& Rata, E. (2016). Comparing curriculum types: Powerful knowledge and $21^{\text {st }}$ century learning. New Zealand Journal of Educational Studies, 51(1), 53-68. https:// doi.org/10.1007/s40841-015-0025-9

[13] Maton, K., \& Moore, R. (Eds.). (2010). Social realism, knowledge and the sociology of education: Coalitions of the mind. Continuum.

[14] Muller, J. (2000). Reclaiming knowledge: Social theory, curriculum and education. Routledge.

[15] Young, M. F. D. (2008). Bringing knowledge back in: From social constructivism to social realism in the sociology of education. Routledge.

[16] Johnson, J. A. (2001, August 28). Curriculum revision that works. In principles of effective change.

[17] Alsubaie, M. A. (2016). Curriculum development: Teacher involvement in curriculum development. Journal of Education and Practice, 7(9), 106-107. http://www.iiste.org/

[18] Shakespeare, P., \& Hutchinson, S. (2007). Curriculum, quality and competencies. In Proceedings of the Sixth World Association for Cooperative Education: Annual International Symposium. Charleston: Wage.

[19] Khan, R. A., Spruijt, A., Mahboob, U., \& Van Merrienboer, J. J. (2019). Determining "curriculum viability' through standards and inhibitors of curriculum quality: a scoping review. BMC medical education, 19 (1), 1-11. https://doi.org/10.1186/s1290 9019-1759-8 
[20] Wolf, P., Evers, F., \& Hill, A. (2006). Handbook for curriculum assessment. Ontario: University of Guelph.

[21] Posner, G. J. (2004). Analyzing the curriculum (3 ${ }^{\text {rd }}$ ed.). New York, NY: Jane E. Karpacz.

[22] Boyd, S., \& Hipkins, R. (2012). Student inquiry and curriculum integration: Shared origins and points of difference (Part A). Set: Research Information for Teachers, (3), 15-23.

[23] Anosike, P., Ehrich, L. C., \& Ahmed, P. (2012). Phenomenology as a method for exploring management practice. International Journal of Management Practice, 5(3), 205-224.Retrieved from http://www.inderscience.com/

[24] Gentles, S. J., Charles, C., Ploeg, J., \& McKibbon, K. (2015). Sampling in qualitative research: Insights from an overview of the methods literature. The Qualitative Report, 20(11), 1772-1789.

[25] Tai, J., \& Ajjawi, R. (2016). Undertaking and reporting qualitative research. Clinical Teacher, 3 , 175. https://doi.org/10.1111/tct.12552

[26] Moser, A., \& Korstjens, I. (2018). Series: Practical guidance to qualitative research. Part 3: Sampling, data collection and analysis. European Journal of General Practice, 24(1), 9-18. https://doi.org/10.1080 /13814788.2017.1375091

[27] Ministry of education, culture \& higher education. (2020). Press release. https://www.somalia online. com/community/topic/183905-shaxda-imtixaanka wasaaradda-ee-dugsiyada-sare oo-ay-fariisteen 33727-waxaa-haray-8550/

[28] Neutens, J. J., \& Rubinson, L. (2010). Research techniques for the health sciences ( $4^{\text {th }} \mathrm{ed}$.). San Francisco, CA: Pearson Education, Inc.

[29] Giorgi, A. (1975). An application of phenomenological method in psychology. Duquesne Studies in Phenomenological Psychology, 2, 82-103. https://doi.org/10.5840/dspp197529

[30] Jacob BA (2005) Accountability, incentives and behavior: the impact of high stakes testing in the Chicago Public Schools. The Journal of Public Economics 89:761-796

[31]Fix, G. M., Ritzen, H. M., Pieters, J. M., \& Kuiper, W, K. (2019). Effective curricula for at risk students in vocational education: A study of teachers' practice. Empirical Research in Vocational Education and Training, 11(1), http://doi.org/10.1186/s40461-018 0076-5

[32] Brink, M., \& Bartz, D. E. (2017). Effective use of formative assessment by high school teachers.

Practical Assessment, Research \& Evaluation, 22, 8. http://doi.org/10.7275/p86s-zc41

[33] Ardzejewska, K., McMaugh, A. \& Coutts, P. (2010). Delivering the primary curriculum: The use of subject specialist and generalist teachers in NSW.
Issues in Educational Research,20(3), 203-219.http: //www.iier.org.au/iier20/ ardzejewska.html

[34] Hennessy, S. (2000). Overcoming the red feeling: The development of confidence to teach Musicin primary school amongst student teachers. British Journal of Music Education, 17, 183-196.

[35] Wilson, G.B., Macdonald, R.A.R., Byrne, C., Ewing, S., \& Sheridan, M. (2008). Dread and passion: Primary secondary teachers' views on teaching the arts. Curriculum Journal, 19, 37-53.

[36] Ojukwu, M. O. (2016). Perception of students on causes of poor performance in chemistry in external examinations in umuahia north local government of abia state. International Journal of Education \& Literacy Studies, 4(1), 67-73. http://dx.doi.org/ 10.7575/aiac.ijels. v.4n.1p.67

[37] Adelodun, G. A., \& Asiru, A. B. (2015). Instructional Resources as Determinants of English Language Performance of Secondary School High-Achieving Students in Ibadan, Oyo State. Journal of Education and Practice, 6(21), 195-200.

[38] Zhonggen, Y. (2019). Video lecturing in clicker assisted English flipped class. PLoS One, 14(10). https://doi.org/10.1371/journal.pone.0224209

[39] Evans H., K. (2014). An experimental investigation of videotaped lectures in online courses, TechTrends, 58(3), 63-70.

[40] Çakir, I. (2015). Instructional materials commonly employed by foreign language teachers at elementary schools *. International Electronic Journal of Elementary Education, 8(1), 69-81.

[41] Waniek, I., \& Nae, N. (2017). Active learning in Japan and Europe. Euromentor Journal, 8(4), 82-97.

[42] McGreevy, K. M., \& Church, F. C. (2020). Active learning: Subtypes, intra-exam comparison, and student survey in an undergraduate biology course. Education Sciences, 10(7), 185.https://doi.org/ 10.3390/educsci10070185

[43] Brigati, J. R., England, B. J., \& Schussler, E. E. (2020). How do undergraduates cope with anxiety resulting from active learning practices in introductory biology? PLoS One, 15(8) http://doi. org/10.1371/journal.pone.0236558

[44] Auerbach, A. J, \& Schussler, E. E. (2016). Instructor use of group active learning in an introductory biology sequence. Journal of College Science Teaching. 45(5):67-74.

[45] American Association for the Advancement of Science. (2011). Vision and Change in Undergraduate Biology Education: A Call to Action.

[46] Khaddage, F., Müller, W., \& Flintoff, K. (2016). Advancing mobile learning in formal and informal settings via mobile app technology: Where to from here, and how? Journal of Educational Technology \& Society, 19(3), 16-26. 
[47] Sefton-Green, J. (2004). Literature review in informal learning with technology outside school. A NESTA Future lab Series (Report 7).

[48]Uden, L. (2007). Activity Theory for Designing Mobile Learning. Journal of Mobile Learning and Organization, 1 (1), 81-102.

[49] Vlanti, S. (2012). Assessment practices in the english language classroom of greek junior high school. Research Papers in Language Teaching and Learning, 3(1), 92-122,316.
[50] Babinčáková, M., Ganajová, M., Sotáková, I., \& Bernard, P. (2020). Influence of formative assessment classroom techniques (facts) on Student's outcomes in chemistry at secondary school. Journal of Baltic Science Education, 19(1), 36-49. http://doi. org/10.33225/jbse/20.19.36

[51] Srivastava, T. K., Mishra, V., \& Waghmare, L. S. (2018). Formative assessment classroom techniques (FACTs) for better learning in pre-clinical medical education: A controlled trial. Journal of Clinical and Diagnostic Research, 12(9). https:/doi.org/10.7860/ JCDR/ 2018/35622.11969

\section{Creative Commons Attribution License 4.0} (Attribution 4.0 International, CC BY 4.0)

This article is published under the terms of the Creative Commons Attribution License 4.0

https://creativecommons.org/licenses/by/4.0/deed.en_US 